\title{
Programas neoestructurales en sociedades conflictivas. El caso del Plan Austral en Argentina (1985-1988)*
}

\author{
Neo-structural programmes in conflict-ridden societies. The \\ case of Plan Austral in Argentina (1985-1988)
}

Programas neoestruturais em sociedades conflitivas. O caso do Plano Austral na Argentina (1985-1988)

Germán Sanhueza Muñoz**

\begin{abstract}
RESUMEN
El artículo repasa la teoría del conflicto social y la corriente de pensamiento neoestructuralista en las políticas públicas de América Latina, específicamente en el diseño e implementación del denominado Plan Austral, aplicado en Argentina entre 1985 y 1988, bajo el mandato del presidente Raúl Alfonsín. La elección de este programa se circunscribe en el estudio de la sociología del desarrollo en América Latina, en el contexto de sociedades conflictivas. Resulta relevante en este ámbito, situar la puesta en marcha de dicho plan, debido a que es posible acercarse al tratamiento del concepto de sociedades conflictivas, tal como lo desarrolló entre otros, el pensador germano-británico Ralf Dahrendorf. La investigación se diseñó desde un paradigma interpretativo con un enfoque fenomenológico, enfatizando el análisis discursivo. Se realizó un trabajo de análisis de documen-
\end{abstract}

Palabras clave: análisis sociológico, Argentina, neoestructuralismo, Plan Austral, teoría del conflicto social.

\footnotetext{
* Esta investigación es fruto de la experiencia del autor en el FONDECYT de Iniciación a la Investigación 2015 № 11150026: "Una alianza para la democracia: la Fundación Ford y el circuito latinoamericano de centros académicos independientes en tiempos de autoritarismo (1969-1990). Un análisis de los casos de CEDES, CEBRAP y CIEPLAN", a cargo del Dr. Juan Morales Martín.

** Chileno. Doctorante en Ciencias Sociales de la Universidad Católica de Murcia UCAM, España. Sociólogo, Administrador Público y Magíster en Políticas Públicas. Profesor Adjunto de la Escuela de Administración y Economía y de la Escuela de Sociología de la Universidad Católica Silva Henríquez y académico del área de Administración de la Universidad Tecnológica de Chile, INACAP, sede Santiago Centro. Murcia, España. smgerman@alu.ucam.edu
} 
tos y de entrevistas a políticos y economistas que participaron en el equipo que diseñó e implementó este programa de gobernanza económica.

\begin{abstract}
This article reviews the theory of social conflict and the neostructuralist school of thought in Latin American public policies, specifically in the design and implementation of the so-called Austral Plan, applied in Argentina between 1985 and 1988, under the mandate of President Raúl Alfonsín. The choice of this program is circumscribed by the study of the sociology of development in Latin America, in the context of conflict societies. It is relevant in this context to situate the implementation of this plan, because it is possible to approach the treatment of the concept of conflictive societies, as developed by the German-British thinker Ralf Dahrendorf and others. The research was designed from an interpretative paradigm with a phenomenological approach, emphasizing discursive analysis. A document analysis and interviews with politicians and economists who participated in the team that designed and implemented this economic governance program were carried out.
\end{abstract}

\section{RESUMO}

O artigo revisa a teoria do conflito social e a corrente neoestruturalista de pensamento nas políticas públicas latino-americanas, especificamente na concepção e implementação do chamado Plano Austral, aplicado na Argentina entre 1985 e 1988, sob o mandato do Presidente Raúl Alfonsín. A escolha deste programa está circunscrita ao estudo da sociologia do desenvolvimento na América Latina, no contexto de sociedades conflitivas. Neste âmbito, resulta relevante situar a implementação deste plano, pois é possível se aproximar ao tratamento do conceito de sociedades conflitivas como desenvolvido, entre outros, pelo pensador germano-britânico Ralf Dahrendorf. A pesquisa foi desenvolvida a partir de um paradigma interpretativo com uma abordagem fenomenológica, enfatizando a análise discursiva. Foram realizadas análises de documentos e entrevistas com políticos e economistas que participaram da equipe que projetou e implementou este programa de governança econômica.
Keywords: sociological analysis, Argentina, neostructuralism, Plan Austral, social conflict theory.

Palavras-chave: análise sociológica, Argentina, neoestruturalismo, Plano Austral, teoria do conflito social. 


\section{Introducción}

\section{Antecedentes}

La sociología desde un planteamiento disciplinario, entre otros aspectos busca analizar, interpretar y comprender las estructuras y los procesos sociales, utilizando herramientas metodológicas que permiten el logro de análisis en perspectiva temporal, contextual y territorial, asociada al comportamiento de individuos, grupos y, en definitiva, a la sociedad en su conjunto. De esta forma, la sociología genera un sustantivo aporte a las ciencias sociales, en lo concerniente al desarrollo de la era y sociedad modernas.

Dentro de las múltiples áreas de la disciplina sociológica, se encuentra la sociología del desarrollo, que es un área que tuvo su instauración en América Latina con los importantes aportes del sociólogo español José Medina Echevarría, y que establece un énfasis e importancia para el desarrollo social de los países, considerando el contexto económico, social y político, y una mirada en perspectiva histórica de configuración de las estructuras sociales y las formas de producción que respaldan los intercambios económicos entre naciones. La economía del desarrollo se basó en un diálogo fructífero de carácter multidisciplinario, en donde a través de las ciencias jurídicas, economía, ciencias políticas y la sociología, entre otras disciplinas, analizaron patrones de comportamiento cultural e histórico, que condicionaban y vinculaban a América Latina con el resto del orbe en términos de intercambio social y comercial.

En virtud de los antecedentes antes expuestos, el presente artículo, muestra un análisis en perspectiva histórica, del diseño y aplicación de un plan de gobernanza económica llevado a cabo en Argentina entre 1985 y 1988, denominado Plan Austral. Este plan económico fue concebido sobre la base de ideas asociadas al neoestructuralismo latinoamericano y en el contexto de una sociedad argentina que, siguiendo los argumentos de sociólogos como Dahrendorf (1966; 1992; 1993) y Coser (1970), es considerada como una sociedad conflictiva. Este plan fue ejecutado por el primer gobierno de la transición democrática de la nación trasandina, posterior a la dictadura militar que culminó en 1983, bajo la presidencia de Raúl Alfonsín (Alfonsín, 2004; Gargarella y Murrillo, 2016; Garulli 2011a; 2011b; Nudelman, 1987; Pucciarelli, 
2010). Este plan se ha seleccionado como muestra de una experiencia de aplicación de un plan económico que tiene una mirada heterodoxa a nivel de economía normativa, puesto que difiere de las directrices más hegemónicas de la época, lideradas por las pautas del Banco Mundial y del Fondo Monetario Internacional FMI (Delgado, 2013). Esta heterodoxia se expresó en un plan económico que, entre otros aspectos, buscó mitigar de la mejor forma posible las acciones de control de la alta inflación de la época en relación con el costo social para los sectores de menores recursos de la sociedad argentina.

En la primera parte del artículo, se desarrollan los principales antecedentes teóricos y empíricos de la problemática abordada. En la segunda parte se desarrolla con exhaustividad un planteamiento teórico que establece las bases epistémicas de la investigación. Se enfatiza en el desarrollo de la denominada teoría del conflicto social, sustentada en los planteamientos del sociólogo germano-inglés Ralf Dahrendorf y del sociólogo inglés Lewis Coser. La tercera sección establece las bases del diseño y aplicación metodológica del estudio. En este apartado se contempla el paradigma interpretativo de investigación, el alcance cualitativo de análisis, el método hermenéutico y de análisis del discurso, como base para el proceso de análisis de las evidencias empíricas, obtenidas principalmente a través del trabajo de campo ejecutado. Finalmente, la cuarta parte del estudio muestra el análisis de los resultados obtenidos en la investigación y, posteriormente, se finaliza con la conclusión de la investigación presentada.

\section{Contexto de desarrollo e ideas políticas y económicas en Amé-} rica Latina desde la segunda mitad del siglo XX

En términos introductorios, es necesario establecer la revisión de la literatura que ha analizado los conceptos de estructuralismo y neoestructuralismo latinoamericano, fundamentos de la teoría del conflicto social que actuaron como base en la instauración del programa de gobernanza económica en Argentina denominado Plan Austral y que tuvo vigencia entre 1985 y 1988 (Frenklen y Fanelli, 1986).

\section{Estructuralismo latinoamericano}

El estructuralismo latinoamericano se entiende como una corriente de pensamiento y enfoque de aplicación de ideas económicas, que crea 
las bases para caracterizar, comprender y guiar los planes de desarrollo de los países de América Latina en el contexto del desarrollo del siglo XX, en años y décadas posteriores a la Segunda Guerra Mundial (Morales, 2010).

Esta corriente de pensamiento fue guiada inicialmente por el economista argentino Raúl Prebisch, en conjunto con los economistas e investigadores de la Comisión Económica para América Latina y el Caribe, CEPAL (fundada en 1949), tales como Furtado, Fajnzylber y Medina Echevarría. A partir de ello el estructuralismo latinoamericano comienza a alcanzar aceptación entre intelectuales, gobernantes, políticos y economistas, entre otros.

Considerando la importancia del análisis de las causas estructurales del subdesarrollo de los países de América Latina, se configuraron grupos de trabajo compuesto por destacados profesionales de diversas áreas disciplinarias de las ciencias sociales, tales como la economía, la sociología, la ciencia política, entre otras disciplinas.

En este sentido, un aspecto relevante en el debate de los estructuralistas de la región, fue analizar los conceptos de desarrollo y subdesarrollo, ya que no necesariamente este último es parte de un proceso para llegar a un umbral, sino que puede ser más bien una condición dada en forma orgánica y sistemática. Esta reflexión llevaría entre otros importantes aspectos al planteamiento de la denominada teoría de la dependencia, la que fue elaborada por destacados intelectuales entre los que se cuenta a Enzo Faletto y Fernando Enrique Cardoso (Bárcena y Prado, 2015).

El estructuralismo latinoamericano cuestiona el planteamiento de beneficio mutuo asociado al concepto de ventaja comparativa propuesto hace años atrás por el economista David Ricardo, uno de los pensadores de lo que hoy se denomina economía moderna. La tesis Prebisch-Singer planteaba que los países del centro (Europa y Norteamérica) retenían los excedentes de su mayor productividad y que a través del comercio internacional escapaba al exterior ese rendimiento de productividad creado en las economías latinoamericanas, creándose restricciones financieras para la acumulación de capital, base de la conformación de una economía capitalista (Delgado, 2013; Di Filippo, 2009). En el caso argentino, es preciso señalar que tanto el análisis es- 
tructuralista como su avance hacia una mirada neoestructuralista tiene su particularidades, lógicas y matices. Esto, debido a la configuración de la estructura social y del poder político de Argentina y de una constante búsqueda de elementos de desarrollo y equilibrio entre el sistema político, la matriz productiva económica y la cohesión social de la nación, con aciertos y desaciertos (Sztulwark, 2005).

\section{Monetarismo o neoliberalismo}

Otra corriente de pensamiento relevante en la revisión de la literatura es el denominado monetarismo o neoliberalismo, puesto que pone en tensión ciertos postulados del enfoque estructuralista latinoamericano y se tiende a confundir con el enfoque neoestructuralista. Acerca de neoliberalismo se ha escrito una significativa literatura, tanto teórica como de análisis de evidencias empíricas. Los estudios de Mises (1972) plantearon fuertes críticas a la eficiencia en que las burocracias públicas hacían entrega de prestaciones y servicios sociales, lo que se denominó como la crisis del Estado de Bienestar de la década de los setenta. Por su parte Hayek (1976) planteó que las acciones y decisiones económicas de los países y/o naciones, deben sustentarse sobre la base de la libertad, el mercado y la competencia entre los agentes económicos, como el motor de crecimiento y desarrollo tanto social como económico.

Otros aportes teóricos relevantes del neoliberalismo son los estudios de Friedman (1962; Friedman y Friedman, 1980) quien era partidario de promover espacios al concepto de libertad en la economía: libertad de precios, de emprendimiento privado y del comercio internacional. Estudios específicos de los ámbitos de acción del neoliberalismo son los de Poterba (1996), autor que analizó el proceso de provisión mixta de bienes y servicios públicos en América Latina y el mundo, tales como educación, salud, vivienda y seguridad social y que fueron también analizados por otros autores como Ball y Youdell (2008) y Jencks (2002).

\section{Neoestructuralismo}

Se entiende como neoestructuralismo al conjunto de pensamientos que revisan las ideas estructuralistas latinoamericanas de las décadas de los 50, 60 y 70 y las contextualizan en un nuevo escenario de configuración internacional a partir de la década de los 80 y que entra en 
discusión con las ideas neoliberales que estaban preponderando desde la crisis del petróleo (1973) y adquiriendo fuerza entre los gobernantes de diversos países principalmente desarrollados (Foxley, 1975; Mallorquín, 2017; Morales e Ibacache, 2018).

En efecto, el neoestructuralismo se reconoce como un esfuerzo teórico e instrumental, que adapta los argumentos estructuralistas latinoamericanos, guiados entre otros por Raúl Prebisch y los economistas de la CEPAL, y avanza en comprender un nuevo contexto internacional, logrando guiar las acciones de economía de los países de la región, a partir de las últimas dos décadas del siglo XX. Entre otros aspectos, el neoestructuralismo se preocupa de promover la estabilidad económica de los países, a través de los esfuerzos del sector público y privado, la sostenibilidad ambiental, el crecimiento con mayor igualdad en la distribución de los ingresos (Bárcena y Prado, 2015). En este sentido, resultan importantes los aportes planteados por Ffrench Davis (1988) y Bitar (1988), ya que enuncian y explicitan elementos conceptuales del neoestructuralismo. La confluencia entre el rol relevante del Estado y la promoción del mercado como motor de la producción y demanda agregada es parte de las ideas neoestructurales. Ffrench Davis (1988), enfatiza que en el enfoque neoestructural los ajustes de los planes económicos de estabilización son gradualistas, prestan especial atención a los procesos de ajustes y sus acciones correctivas, consideran la variable contextual y sociohistórica en la gestión de la gobernanza y promueven una distribución más adecuada del poder e inserción en la economía mundial, en donde finalmente el Estado cumple la función de impulsar acciones concretas para el bienestar social nacional (Heredia, 2015).

En el caso de Argentina, centros académicos como el Instituto de Desarrollo Económico y Social (IDES) funcionaron en tiempos de la dictadura militar argentina como una "organización paraguas", esto es, como un foro, punto de encuentro y lugar de enseñanza y difusión para varios grupos de investigadores argentinos. La revista académica publicada por el IDES, Desarrollo Económico, llegó a ser reconocida internacionalmente como una de las revistas académicas más importantes en el ámbito económico, no solamente de Argentina, sino de América Latina. El director del IDES durante 1972-1983 fue Juan Vital Sourrouille, quien de hecho también había sido un becario de la Fundación Ford en la Universidad de Cornell. 
A su vez, el Centro de Estudios de Estado y Sociedad (CEDES) jugó un rol importante en Argentina, en ampliar horizontes de pensamiento político, económico y sociológico. Durante los años 1976-1982 Adolfo Canitrot del CEDES fue el director de la revista Desarrollo Económico, y su cargo como director durante estos años facilitó la publicación de trabajos de los investigadores del CEDES y del Centro de Investigaciones Sociales sobre el Estado y la Administración (CISEA) en casi cada edición de la revista. Esto explica las relaciones entre CEDES y el IDES, y que luego tres miembros del CEDES ocuparan cargos en el gobierno de Alfonsín: Oscar Oszlak fue nombrado el subsecretario de Reforma Administrativa, un cargo que ocupó durante todo el mandato de Alfonsín, en tanto que Adolfo Canitrot y Roberto Frenkel, fueron parte del equipo económico del Ministerio de Economía de Juan Vital Sourrouille: Canitrot ocupó el cargo del subsecretario General de Planificación durante entre 1983 y 1985 y luego fue el viceministro de Economía entre 1985 y 1989; Frenkel, por su parte, fue nombrado subsecretario y jefe de Asesores del Ministerio de Economía.

\section{Teoría del conflicto y el concepto de sociedades conflictivas}

Los fundamentos teóricos de la teoría del conflicto social, se desarrollan durante la segunda mitad del siglo XX, con posterioridad al término de la Segunda Guerra Mundial, principalmente tras analizar el nuevo contexto económico, político y social de naciones industrializadas en Norteamérica y Europa. Quienes han aportado al desarrollo conceptual de este objeto de estudio son los sociólogos Ralf Dahrendorf y Lewis Coser que estudiaron, entre otros aspectos, las formas y mecanismos de construcción y desencadenamiento del conflicto social. Dahrendorf (1992; 1993) plantea que el conflicto social se manifiesta en el contexto de la consolidación de los estados modernos, en específico en las estructuras capitales del eje occidental.

El argumento central es que las inestabilidades sistemáticas en la estructura social -que por definición son parte de la esencia de las interacciones sociales-, repercuten directamente en las formas y acciones de gobernanza de la política, es decir, el ejercicio legítimo del poder, de la autoridad, de las formas de acción política y, en última instancia, también en las formas de coacción del poder político (Dahrendorf, 1992). 
En su planteamiento teórico, Dahrendorf presenta varias interrogantes para avanzar en la teoría del conflicto social. Al respecto, señaló:

¿Cuáles son las dimensiones de variabilidad de determinadas especies de conflictos sociales y en qué condiciones varían las formas conflictivas dentro de estas dimensiones? Es esta la cuestión más fructífera de una teoría sociológica del conflicto, tanto en el aspecto teórico como político. Su contestación facilita la comprensión de la creciente o menguante intensidad y violencia de los conflictos sociales, y con ello permite señalar los momentos en que parece posible, al menos en teoría, una intervención directora. (Dahrendorf, 1992, p.183).

¿De qué modo pueden regularse los conflictos sociales? En sentido estricto este último problema de una teoría del conflicto, es solo un aspecto del anterior. Sin embargo, puede justificarse su tratamiento por separado en cuanto que la regulación de los conflictos sociales hace surgir, por una parte, un campo de factores propio y, por otra, lleva de nuevo a la problemática general del conflicto. (Dahrendorf, 1992, p. 183).

Por su parte Coser (1970) plantea que esta dinámica del conflicto social se desenvuelve bajo cierta premisa: la mejor estructuración de los cuerpos sociales, se ve reflejada por ejemplo en negociaciones entre detentores legítimos de poder y autoridad, mediando el conflicto y procediendo a la estabilidad de los sistemas políticos, entre otros. Esta premisa se cumple sobre la base de un cierto tipo de cultura política de una sociedad en específico, es decir, una estructura social que ha desarrollado y madurado las formas de acción colectiva.

Los alcances del concepto de conflicto en una sociedad según el autor, se pueden observar a modo de ejemplo en los siguientes extractos:

El conflicto con otros grupos contribuye a establecer y reafirmar la identidad del grupo propio y mantiene sus fronteras con relación al mundo social que lo rodea. Las enemistades consagradas y los antagonismos recíprocos conservan las divisiones sociales, y los sistemas de estratificaciones. Esos antagonismos tradicionales impiden la desaparición social, y determinan la posición de los diversos subsistemas dentro de un sistema total. (Coser, 1970, p. 18). 
En las estructuras sociales que procuran un amplio margen de movilidad, es muy probable que exista atracción de los estratos elevados sobre los inferiores, así como hostilidad mutua entre los estratos. En este caso es frecuente que los sentimientos hostiles de los estratos inferiores tomen la forma de resentimiento, en la que la hostilidad va mezclada con la atracción. Esas estructuras tenderán a suministrar muchas oportunidades conflictivas, puesto que... la frecuencia de las posibilidades de conflicto varía directamente de acuerdo con la intimidad de las relaciones (Coser, 1970, p. 19).

Respecto de la relación entre conflicto social e interacción social, el autor menciona:

Conflicto social siempre denota una interacción social, en tanto que las actitudes o sentimientos son predisposiciones a entrar en acción, estas predisposiciones no conducen necesariamente al conflicto, el grado y el género de legitimidad que posean el poder y los sistemas establecidos son variables decisivas que afectan el crecimiento del conflicto. (Coser, 1970, p. 32).

De acuerdo con lo planteado por Coser, es posible relevar la relación entre los procesos de interacción social y la naturaleza y dinámica del conflicto, es decir, la vinculación entre grupos y la sociedad en su conjunto.

\section{Preguntas de investigación y síntesis de la problemática}

La problemática de investigación se centra en abordar en forma comprensiva, desde una mirada sociológica, las condiciones y efectos que tuvo la aplicación de un plan macroeconómico bajo un enfoque neoestructuralista, como lo fue el Plan Austral (1985-1988). Esta problemática será guiada a través de la pregunta: ¿Cómo se puede comprender desde la teoría del conflicto social la aplicación de una política económica neoestructural en Argentina entre 1985 y 1988 ?

\section{Metodología}

\section{Estudio de alcance cualitativo}

Se estableció que lo más pertinente a la investigación era el diseño y aplicación de un estudio con metodología cualitativa. A partir de lo propuesto por Canales (2013) y Quecedo y Castaño (2002), los estudios 
cualitativos enfatizan la interpretación de fenómenos contextualizados en ciertos espacios temporales y desde diversas perspectivas de análisis.

Paradigma de investigación: interpretativo con enfoque fenomenológico y sociohistórico

El paradigma de investigación utilizado fue el interpretativo, incorporando el enfoque fenomenológico y el sociohistórico, con énfasis en los análisis discursivos. Se consideró esta decisión metodológica, puesto que los estudios de carácter cualitativo que utilizan enfoques fenomenológicos y sociohistóricos se caracterizan por analizar las experiencias individuales y grupales de los participantes de una experiencia vivida, atribuyendo importancia a la variable histórica para los procesos de interpretación cualitativa (Aróstegui, 1990).

\section{Alcance y lógica de la investigación: interpretativo}

El alcance y la lógica de investigación fueron de carácter interpretativo e inductivo. Respecto del primer componente señalado, Canales (2013) establece que los estudios de alcance cualitativo tienen como principal cualidad y característica el abordar un análisis interpretativo de un objeto de estudio contextualizado en circunstancias específicas, abriendo de esta forma espacios de nuevos análisis o perspectivas, lo que concuerda adecuadamente con el estudio de caso del Plan Austral.

\section{Método de investigación: estudio de caso}

Se seleccionó el estudio de casos porque este método permite investigar fenómenos en los que se buscar dar respuesta al contexto y a las formas de ocurrencia de un fenómeno de estudio en particular, logrando analizar desde diversas perspectivas hechos, contingencias, lo que sin duda nutre al investigador de una ventana de oportunidades de exploración y amplitud en la comprensión de un objeto de estudio (Martínez Carazo, 2006).

\section{Técnicas de recogida de información o fuente de información}

Siguiendo los argumentos de Salgado (2007) y Hernández et al. (2014), los diseños de investigación cualitativa deben colocar especial énfasis en las técnicas y fuentes de información que permitirán el logro de los 
objetivos de la investigación y analizar adecuadamente la problemática establecida en el estudio. En términos de técnica, se utilizará el mecanismo de análisis de contenido y de documentos de las fuentes de investigación que se describen en los siguientes párrafos.

El análisis contempla la visión inicial de la sociedad argentina, la puesta en marcha del Plan Austral, su éxito inicial y posterior fracaso y los discursos reflexivos realizados 30 años después, por parte de los economistas y políticos que llevaron a cabo este plan de gobernanza económica, comprendiendo de mejor forma los motivos de este fracaso. Esto lleva a reforzar la idea de un análisis interpretativo en perspectiva histórica.

Lo anterior se complementa con el análisis del libro La Política Económica en una sociedad conflictiva: el caso argentino (Mallom y Vital Sourrouille, 1973) y del Plan Austral, particularmente de la ley que informa de las medidas de estabilización económica de la Argentina, promulgada a través del Decreto Nacional $\mathrm{N}^{\circ} 1.096$ del 17 de junio de 1985, y que tuvo vigencia hasta el año 1988.

Se suma a lo anterior el análisis de contenido audiovisual de los mensajes a la nación Argentina del presidente Alfonsín y del ministro Vital Sourrouille, junto con los contenidos temáticos de los mensajes oficiales transmitidos por cadena de televisión y radio, emanados por el presidente de la República Argentina, Raúl Alfonsín y del ministro de Economía, Juan Vital Sourrouille, informando a la nación de la instauración del Plan Austral en 1988.

Por último, se realizó un trabajo de campo con análisis de un conjunto de entrevistas disponible en el Archivo de Historia Oral, del Instituto de Investigaciones Gino Germani, organismo académico creado en 1940, y que en la actualidad es una unidad académica dependiente de la Facultad de Ciencias Sociales de la Universidad de Buenos Aires, Argentina.

Modo de análisis: análisis de contenido y de documentos sobre la base de categorías y subcategorías

En función de las técnicas antes descritas, el análisis interpretativo de contenidos y de documentos relevantes para esta investigación fue guiado por categorías y subcategorías que se describen en la Tabla 1. 
Tabla 1

Categorías de análisis y sub-categorías de análisis ${ }^{1}$

\begin{tabular}{ll}
\hline Categorías de análisis & Subcategorías de análisis \\
\hline CA1 El conflicto social & Características del conflicto social \\
en Argentina & $\begin{array}{l}\text { Identificación de una sociedad conflictiva } \\
\text { Actores y sus acciones en un conflicto social }\end{array}$ \\
\hline CA2 & El rol del Estado bajo el enfoque \\
Neoestructuralismo & $\begin{array}{l}\text { neoestructuralista } \\
\text { Inserción en la economía mundial } \\
\end{array}$ \\
& Gradualismo de las acciones de gobernanza \\
& Contenido del Plan Austral \\
\hline CA3 Alcances del Plan & Efectos del Plan Austral \\
Austral & Fracaso y suspensión del Plan Austral \\
\hline
\end{tabular}

\section{Criterios de rigor éticos y científicos}

Uno de los aspectos que adquieren relevancia en el diseño y aplicación de estudios de carácter cuantitativo y cualitativo lo constituyen los criterios de rigor éticos y científicos (Noreña et al., 2012). Los principales criterios éticos utilizados en la investigación fueron el apego a la verdad, confidencialidad y reflexividad objetiva. Por su parte, los criterios científicos utilizados fueron credibilidad, aplicabilidad, consistencia y objetividad.

\section{Análisis de los resultados}

En el siguiente apartado se presentan los elementos esenciales del análisis de los resultados de la investigación. El análisis se sustenta principalmente en el trabajo de campo realizado en el Instituto de Estudios

1 En el contexto de una etapa denominada trabajo de campo de la presente investigación, se realizó una breve estancia de investigación en Buenos Aires, Argentina, entre los días 1 y 9 de agosto de 2019. En lo específico, se visitó el Archivo de Historia Oral, perteneciente al Instituto de Investigaciones Gino Germani, de la Facultad de Ciencias Sociales de la Universidad de Buenos Aires. En este archivo se encuentran, entre otras fuentes primarias relevantes, entrevistas a personeros de gobierno, intelectuales y académicos que fueron protagonistas de la historia de Argentina a contar de la segunda mitad del siglo XX. Si bien es cierto las fuentes no fueron elaboradas ni aplicadas por el investigador de este artículo, resultan fuentes validadas por instituciones académicas y públicas de Argentina, ya que obran como una especie de archivo patrimonial de los relatos de parte de la historia trasandina en las últimas décadas del siglo XX y principios del siglo XXI. 
Gino Germani, de la Facultad de Ciencias Sociales de la Universidad de Buenos Aires, Argentina.

El Plan Austral en una sociedad conflictiva. El libro de Mallom y Vital Sourrouille y otros textos

Como se mencionó, el Plan Austral fue un programa de estabilización económica impulsado y ejecutado por el presidente Raúl Alfonsín entre los años 1985 y 1988. Su objetivo principal fue tomar decisiones de política monetaria que revirtieran el alto índice de inflación e inestabilidad económica que vivía Argentina después del término de la dictadura militar, es decir, durante el desarrollo de la década de los 80 . Respecto de este plan se han escrito numerosos estudios, debido a que se trató de una iniciativa con ideas heterodoxas que finalmente no fructificaron en el tiempo, pero que dejaron en evidencia diversas opciones de gobernanza económica, distintas de las directrices hegemónicas de política económica, impulsadas a contar de la segunda mitad del siglo XX por parte de organismos internacionales como el FMI y el Banco Mundial, entre otros. Durante la década de los 80, fue recurrente en las directrices emanadas de estos organismos internacionales, la sugerencia técnica hacia la aplicación de políticas de shock para estabilizar en el corto y mediano plazo, la alta inflación y el gasto público. Dada la configuración de la sociedad argentina, este plan pretendió alejarse de esta noción ortodoxa y tener un enfoque gradualista con los menores costos sociales posibles (Delgado, 2013; Gerchunoff y Rapetti, 2016) desde una mirada de economía política.

Ahora bien, en cuanto al libro de Richard Mallon y Juan Vital Sourrouille, publicado en el año 1973 y que llevó por nombre La política económica en una sociedad conflictiva. El caso de Argentina, este se escribe 12 años antes de la puesta en marcha del Plan Austral, y contextualiza desde una perspectiva teórica y de evidencias empíricas, la configuración y actuación de planes de gobernanza económica en espacios institucionales, sociales y políticos, propios de sociedades donde impera el conflicto social y, por ende, inciden directamente en las posibilidad de desarrollo económico y bienestar en una perspectiva de largo plazo (Mannheim, 2018).

Al respecto, resulta importante citar lo planteado por Mallom y Vital Sourrouille (1973), respecto de la aplicación de planes de gobernanza 
económica en sociedades conflictivas. Bajo esta línea argumentativa, los autores expresaron:

Las dificultades que entraña conciliar un crecimiento más rápido con el equilibrio interno y externo están ampliamente demostradas por la experiencia de las economías avanzadas; pero además de ello, otras dos clases de limitaciones complican la conducción de la política macroeconómica en los países menos desarrollados. Una de estas limitaciones consiste en la mayor dependencia directa de las economías menos desarrolladas con respecto a sectores foráneos. Esto resulta por demás obvio cuando, por ejemplo, la exportación genera la mayor parte del ingreso monetario, los impuestos sobre el comercio exterior son la principal fuente de ingresos fiscales, y las subsidiarias locales de los bancos y empresas extranjeras pueden aislarse de las políticas monetarias merced a su acceso a la financiación foránea. La segunda clase de limitaciones especiales en la conducción de la política macroeconómica de los países en desarrollo consiste en el alto grado de conflicto sociopolítico. Desde luego que el conflicto es una experiencia humana universal, pero en las sociedades más avanzadas las instituciones actúan como mediadoras y reprimen o moderan sus manifestaciones más extremas. En ellas ha sido posible establecer instituciones relativamente fuertes y respetadas, tales como tesorerías y bancos centrales que manejan la política macroeconómica de acuerdo con ciertas reglas de juego que gozan en general aceptación. Esto es menos cierto en los países en desarrollo que no están regidos por un partido único poderoso o por un gobierno totalitario. Más generalmente, las coaliciones forjadas en una nueva etapa inicial para apoyar ciertas reglas de juego, tratan en ocasiones de ser desarticuladas por la emergencia de nuevos y cada vez mejor organizados grupos de intereses. (p. 7).

Desde el punto de vista analítico, resulta relevante sustentar que tanto Mallom y Vital Sourrouille (1973) como otros autores desde el punto de vista de caracterización establecen a Argentina como una sociedad conflictiva. Esta base se encuentra en la sociología del conflicto y en elementos de ciencia política vinculados con la configuración del poder, autoridad política y su relación con la estructura social (Mallom y Vital Sourrouille, 1973; Murmis y Portantiero, 2011). 
Análisis cualitativo de los resultados de la investigación ${ }^{2}$

A continuación se muestra el resumen de las entrevistas analizadas en el trabajo de campo, y que forman parte de la base del análisis del discurso de los actores involucrados directamente en el diseño y la gestión del Plan Austral de Argentina (1985-1988) ${ }^{3}$.

\section{Origen del Plan Austral}

El Plan Austral se diseñó en el contexto de una delicada situación económica que enfrentaba Argentina desde los inicios de la década de los 80. En 1985 el país trasandino experimentaba una hiperinflación superior al $500 \%$, lo que generaba una profunda inestabilidad política del primer gobierno de transición democrática, encabezado por el presidente Raúl Alfonsín. A continuación, se realizará un breve análisis sobre la base de los planteamientos de personeros directamente vinculados con el diseño y puesta en marcha del Plan Austral:

\section{Situación económica de la Argentina}

La condición económica heredada de la gestión del régimen militar era muy deficiente, lo que por cierto establecía importantes desafíos al primer gobierno democrático de la transición argentina. Frente a este escenario, el presidente Alfonsín expresó:

Era fundamental establecer bases de una coincidencia programática con el peronismo, para poder gobernar y hacer frente al proyecto político y a los acuerdos para hacer resurgir la economía.

Una labor importante era renegociar la deuda. Para lograr ese objetivo, una de las cosas que se realizaron fue gestionar conversaciones con Ronald Reagan. (Entrevista Raúl Alfonsin, 2005).

2 Cabe recalcar que los extractos de las transcripciones de las entrevistas señaladas en el presente artículo, fueron obtenidas del Archivo de Historia Oral, perteneciente al Instituto de Investigaciones Gino Germani, de la Facultad de Ciencias Sociales de la Universidad de Buenos Aires.

3 Es importante precisar que la selección de entrevistas analizadas aportan una reflexión directa de los economistas argentinos que estuvieron directamente vinculados con el manejo macroeconómico del país durante el período previo, durante y posterior a la aplicación del Plan Austral. Justamente en esta condición de decisión metodológica, se entregan fragmentos de las entrevistas, para que el lector del artículo construya su propia opinión referente al contexto histórico vivido por Argentina durante parte de la década de los $80 \mathrm{y}$, por ende, es una de las tantas visiones válidas que se pueden obtener de lo experimentado en esos momentos. 
De acuerdo con las palabras del ministro de Economía del presidente Alfonsín, Juan Vital Sourrouille, los antecedentes eran los siguientes:

Las finanzas públicas de Argentina eran un desastre, con un nivel de deuda pública inmanejable y con una política monetaria de cambio fijo, que generaba una inestabilidad constante, en un contexto donde la prioridad era mantener cierta estabilidad para darle un adecuado soporte al gobierno democrático.

La inflación era incontrolable, y frente a ese escenario la prioridad era frenarla. Para lograr ese objetivo existían dos caminos: medidas gradualistas o una política de corte inmediato. (Entrevista Juan Vital Sourrouille, 2005).

Estos planteamientos, se conjugan con lo planteado por Vital Sourrouille años atrás, desde una posición académica, en términos de insertar definitivamente a Argentina en un contexto de economía mundial globalizada e interdependiente, promoviendo la apertura de producción e inversiones de empresarios trasandinos. Estos elementos refuerzan el enfoque neoestructural en las ideas del ministro de Economía de esa época y abren una permanente discusión acerca de nuevas formas de equilibrio actual entre el crecimiento económico y el bienestar de la sociedad, sobre todo en los sectores socioeconómicos de mayores carencias y necesidades. Por su parte, José Luis Machinea, expresó en relación con este contexto:

Con Bernardo Grispun la inflación estaba por las nubes y por ende era fundamental negociar con el FMI, ya que existían graves problemas para pagar la deuda. Los salarios reales cayeron, por lo que la situación era tensa. Desde luego, negociar con el FMI involucraba seguir las pautas asociadas a políticas ortodoxas de shock, lo que por cierto era una discusión importante con Juan Vital Sourrouille, Adolfo Canitrot, Mario Brodersohn y yo. (Entrevista José Luis Machinea, 2005).

Carlos Bonvecchi, por su parte, reflexionó lo siguiente:

La inflación en Argentina en los ochenta era incontrolable y con un tipo de cambio fijo que no aportaba a la estabilidad de precios. Adicionalmente, los sindicatos presionaban por aumentos salariales. Todo este panorama, afectaba gravemente a un déficit fiscal que cada vez se tornaba más inmanejable. (Entrevista Carlos Bonvecchi, 2005). 
De acuerdo con los planteamientos analizados, es posible observar puntos de confluencia respecto de la situación de diagnóstico del escenario económico de Argentina: un alto nivel de inflación que afecta directamente la estabilidad y desarrollo de la sociedad argentina; un tipo de cambio fijo que presiona a la inflación y constituye una constante en el país trasandino, es decir, al no tener confianza en su moneda nacional, las personas, familias, empresas e inversionistas, se refugian en los dólares. Finalmente, esta situación desencadena adicionalmente un aumento constante de la deuda pública, lo que se refleja en una política fiscal deficitaria, que permanentemente obliga a Argentina a renegociar sus deudas con organismos tales como el Banco Mundial y el FMI, entre otros.

\section{Bases del diseño del Plan Austral}

En virtud de la situación delicada y compleja que vivía la Argentina en 1985, el presidente Raúl Alfonsín, decide realizar un cambio de gabinete: deja el Ministerio de Economía el economista Bernardo Grispun, y asume esta importante función el economista Juan Vital Sourrouille, quien hasta esa fecha ocupaba el cargo de secretario de Planificación.

Respecto del diseño de las bases del Plan Austral, Vital Sourrouille señala en la entrevista analizada:

Un imperativo urgente era frenar la hiperinflación, reconstruir la gestión de las finanzas públicas y construir un camino de solución para la deuda pública, que en esa fecha era absolutamente incompatible con políticas de desarrollo y bienestar de la sociedad, que pretendía impulsar el presidente. Frente a esta situación, lo más habitual y normal era negociar con el FMI y aplicar un plan económico asociado a sus políticas ortodoxas.

Entonces, el Plan Austral era en mi interpretación una figura política, que desde lo económico ayudará a disminuir la inflación, pero por sobre todo a sostener el gobierno democrático. $\mathrm{Y}$ a partir de esa premisa, junto al equipo de economistas comenzamos a hablar de un plan distinto, mirado desde la heterodoxia. Frente a esta fórmula, lo más complejo era lograr el apoyo internacional. Por esta razón, viajamos a Washington, en abril de 1985, a conseguir el respaldo de la FED y del gobierno de los Estados Unidos. 
Después de semanas de negociaciones, se logró un acuerdo previo con el FMI, respaldado por Estados Unidos. Posteriormente, Estados Unidos quería cambiar la parte del Plan Austral, referida a establecer un tipo de cambio fijo, ya que iba contra toda la racionalidad de los economistas de la FED, del Banco Mundial y del FMI. (Entrevista Juan Vital Sourrouille, 2005).

Por su parte, José Luis Machinea expresó:

En el FMI estaba Camdessus y buscamos como equipo económico convencer a las personas claves de respaldar el plan. Nos habíamos reunido antes en una especie de cafetería Juan Vital Sourrouille, Adolfo Canitrot, Mario Brodersohn y yo. Teníamos claro que lo más complejo de la discusión era si se aplicaba un enfoque gradual de estabilización de la inflación o una política de shock, y lograr convencer a EE.UU. acerca de un plan heterodoxo, no vinculado a la línea de trabajo regular del FMI. (Entrevista José Luis Machinea, 2005).

Respecto a este mismo ámbito, Bonvecchi indicó lo siguiente:

El Plan Austral se pensaba inicialmente sobre la base de políticas ortodoxas, de corte asociados a los organismos internacionales. Sin embargo, se pensó y buscó otra fórmula, ya que en ese momento las presiones de los sindicatos eran muy fuertes y el presidente $\mathrm{Al}-$ fonsín estaba también preocupado de evitar un golpe de Estado. (Entrevista Carlos Bonvecchi, 2005).

Finalmente, frente a las bases del diseño del Plan Austral, Brodersohn expresó:

Fue importante antes de entrar a conversar con representantes del FMI y de la FED de EE.UU. la conversación que sostuvimos, en que te digo yo como un bar, en Washington, Juan Vital Sourrouille, José Luis Machinea, Adolfo Canitrot y yo, para estar bien claros en cómo íbamos a lograr el respaldo extranjero, porque sin el apoyo, ninguna posibilidad de ningún plan. Además, la preocupación por controlar la inflación no solo era permanente sino que urgente para sostener el gobierno. (Entrevista Mario Brodersohn, 2015).

A partir de las declaraciones expuestas, es posible establecer que las bases del Plan Austral fueron de carácter innovador, heterodoxo, desmarcándose de los planes de corte ortodoxo orientados por las direc- 
trices de organismos internacionales tales como el Banco Mundial y el FMI, entre otros.

Desde un planteamiento sociológico, el diseño del Plan Austral, se realizó con mucha reserva y secretismo, debido a que grupos de interés tales como los sindicatos, dirigentes empresariales y miembros de la oposición política, podían boicotear el plan e impedir su puesta en marcha. Esta situación pone de manifiesto la debilidad en términos de gobernanza y gobernabilidad que debía enfrentar el gobierno del presidente Alfonsín, en un contexto en donde el tramado histórico de conformación del sistema político argentino, dan cuenta de fuerzas políticas con poder e influencia y que configuran a la Argentina como una sociedad conflictiva, en función de los planteamientos teóricos de Dahrendorf, Coser, Mallon y Vital Sourrouille, entre otros.

\section{Aplicación del Plan Austral y su posterior fracaso}

Finalmente, en 1985 entró en vigencia el denominado Plan Austral. A través de un mensaje emitido en cadena nacional el día 14 de junio de ese año, el presidente Raúl Alfonsín y el ministro de Economía Juan Vital Sourrouille, dieron a conocer los planteamientos del plan y sus bases programáticas. En este contexto sociopolítico de la Argentina, el presidente Alfonsín expresó en ese momento:

Así pueblo y gobierno iniciaremos juntos una acción de la cual depende el futuro de la Argentina. El 26 de abril les manifesté que nos encontrábamos frente a una economía de guerra, si es que así se quiere entender a la situación de un país maltratado. Esto no puede ser entendido solo como un conjunto de medidas de gobierno, coyunturales y técnicas. Debe ser además una movilización general de todos los recursos humanos y materiales de la sociedad. Vengo ahora a exponerles el plan de batalla para que todos podamos clausurar definitivamente el capítulo de la decadencia nacional. Porque la Argentina necesita de su pueblo y el pueblo ha decidido ganar la batalla. (Alfonsín, 1985).

Por su parte, el ministro de Economía, Juan Vital Sourrouille manifestó ese mismo día en la cadena nacional, lo siguiente:

El gobierno se dispone a llevar a cabo un ataque firme y en todos los frentes a la inflación. El país se ha desplazado a una situación 
próxima a la hiperinflación, esto es un vertiginoso aumento de los precios que evapora el valor de la moneda y compromete las bases mismas de la convivencia social e institucional de la nación. Es preciso terminar de una vez por todas con la inflación, esta es una demanda que desde todos los sectores, los hogares y las empresas, se dirige hacia el gobierno, y el gobierno va a actuar.

Hay que poner fin a la ansiedad e incertidumbre que genera la aceleración de los precios. Nada se puede construir, nada se puede proyectar en una situación semejante, y los argentinos queremos reconstruir el país, empobrecido y endeudado por políticas antipopulares y queremos proyectarlo hacia adelante, sacándolo del estancamiento y la decadencia. (Sourrouille, 1985).

Respecto de las indagaciones realizadas en relación con la aplicación del Plan Austral, el ministro de Economía Vital Sourrouille expresó años más tarde:

Al día siguiente de los anuncios formales del Plan Austral, hubo una reunión con los radicales en un teatro. Estaba lleno y yo no sabía cómo iba a reaccionar la gente. Se procedió a explicar los alcances de las medidas. Luego de la presentación hubo un gran aplauso de apoyo. Lo que te quiero decir que el apoyo inicial de diversos sectores fue muy grande, además que el plan rápidamente comenzó a dar sus frutos y la inflación comenzó a bajar rápidamente, lo que llevó a la sociedad a reaccionar positivamente. (Entrevista Juan Vital Sourrouille, 2005).

Por su parte, José Luis Machinea manifestó en relación con la implementación del Plan Austral:

El Plan Austral fue muy bueno los tres primeros meses, ya que había un acuerdo transversal y unificado de estabilizar con urgencia la economía nacional. De hecho la economía argentina comenzó a crecer, $10 \%$ el primer semestre de 1985, lo que potenció los apoyos desde los más diversos sectores.

Esto es crucial de entender, puesto que la construcción de acuerdos políticos y sociales en el país con los grupos de interés, se lograba en base al resultado inicial del Plan Austral. El problema posterior fue ceder a la presión de los sindicatos, lo que llevó a aumentar los 
salarios reales, lo que por ende incidió en aumentar el consumo. (Entrevista José Luis Machinea, 2005).

En directa relación con esta línea argumentativa, Carlos Bonvecchi indicó:

Los inicios del Plan Austral fueron muy auspiciosos y se comenzó a lograr plenamente el objetivo pactado. Sin embargo, las presiones salariales por parte de los sindicatos, afectaron el Plan Austral. Alfonsín preocupado de evitar un golpe de Estado, negoció con los sindicatos, es decir, negoció aumento de salarios reales para lograr mayores cuotas de gobernabilidad, lo que mostraba claramente que se trataba de una democracia débil. (Entrevista Carlos Bonvecchi, 2005).

En fuentes complementarias se releva la importancia del análisis de lo planteado por Bonvecchi, en términos de los alcances del concepto de democracia débil, para el caso argentino de la década de los 80. Cabe señalar que el período de transición política de la nación trasandina se vio constantemente amenazada por actos de orden militar o de otros sectores. A modo de ejemplo, se pueden citar los sucesos de Semana Santa de 1987, donde un grupo de militares denominados $c a$ rapintadas, promovió una insurrección castrense, debido al avance de los juicios a grupos de uniformados involucrados en violaciones a los derechos humanos, ocurridos en la dictadura militar trasandina, entre los años 1976 y 1983 (Colomer Viadel, 1995).

\section{Las reflexiones del fracaso}

Uno de los aspectos importantes en las reflexiones de los protagonistas del diseño y ejecución del Plan Austral fueron los comentarios con 30 años de distancia, respecto de los motivos o causas específicas que desembocaron en el fracaso del Plan Austral y su suspensión en 1988, luego de haber realizado un último intento de estabilización monetaria, realizado a través del denominado Plan Primavera. Al respecto, el presidente Alfonsín señaló en el año 2005:

Siempre estuvo la voluntad política de buscar coincidencias programáticas con el peronismo. Sin embargo las tensiones fueron permanentes, con el agravante de la observación de los militares. Es por eso que las condiciones para gobernar fueron siempre difíciles. 
La Confederación General del Trabajo CGT, quería hacer fracasar el Plan Austral. Las presiones por ejemplo para aumentar los salarios reales eran permanentes, y eso desde luego volvía a presionar las cuentas fiscales. Asumo esa responsabilidad de la negociación y por ende la no contención del gasto público. Todo eso y otras cosas más, llevaron a que el Plan Austral fracasara. (Entrevista Raúl Alfonsín, 2005).

En esta misma línea argumentativa, el ministro de Economía, Juan Vital Sourrouille, reflexionó lo siguiente respecto del fracaso del Plan Austral:

Hubo claramente errores de imprevisión a la hora de implementar el Plan Austral, tanto con los inversionistas así como en el consumo interno. Pese a eso comenzó de buena forma, pero se deterioró por dos grandes razones: cambios en la política económica internacional de los Estados Unidos en la segunda parte de la década de los 80, y aceptar la presión y negociar con la Confederación General del Trabajo CGT, el aumento de salarios reales.

La tranquilidad que observo en mi rol, es luchar a través de todos los medios de entregar el gobierno a otra administración democrática, y eso se logró. (Entrevista Juan Vital Sourrouille, 2005).

Por su parte, José Luis Machinea expresó la siguiente reflexión:

La complejidad de relacionarse y negociar con tantos actores sociales y políticos, es muy difícil, sobre todo en Argentina donde se pueden generar huelgas y paros de alcance. Frente a esa tensión, la política económica se deteriora. Eso desde luego también lo vivió Alfonsín y el deterioro posterior del Plan Austral. Las presiones políticas la gran mayoría de las veces afectan cualquier intento de estabilización económica. (Entrevista José Luis Machinea, 2005).

Carlos Bonvecchi, en este mismo contexto de reflexión en perspectiva histórica del fracaso del Plan Austral, señaló:

Se iban a realizar todos los esfuerzos posibles para que Alfonsín terminara su gobierno, o a lo menos entregara el poder a otro demócrata. El Plan Austral se fue degradando y por ende fue menos rígido, se aumentó el gasto público y los términos de intercambio 
aumentaron el precio del dólar, con eso la inflación se volvió a disparar y se tornó inmanejable. De todas formas fue positivo ver cómo Alfonsín logró entregar el gobierno a otra administración democrática. Eso me deja una sensación de gratificación histórica. (Entrevista Carlos Bonvecchi, 2005).

Roberto Lavagna (2007), por su parte, manifestó en la entrevista analizada:

La política monetaria se sustenta en gran parte por la confianza tanto de los actores económicos y políticos de un país. Esa confianza política siempre ha sido tensa, entre el peronismo y las otras fuerzas políticas y los grupos sociales de presión. El caso del Plan Austral fue lo mismo. Cuando la confianza bajó, el plan falló. (Entrevista Roberto Lavagna, 2007).

Carlos Carballo, también realizó su reflexión:

Los planes de estabilización han sido muy difíciles de implementar en la Argentina. En casi todas las ocasiones, las disputas de poder y las negociaciones, desvirtúan la racionalidad técnica de los planes. El Plan Austral partió bien pero fruto de esas negociaciones políticas basadas en la fragilidad permanente de nuestra democracia, impulsaron los resultados negativos hacia finales del 87 y comienzos del 88. (Entrevista Carlos Carballo, 2007).

El historiador y economista argentino, Pablo Gerchunoff realizó la siguiente reflexión:

Negociar es parte del juego democrático, pero acá los sindicatos ejercen un poder e influencia inusual, lo que afecta la gestión gubernamental.

Después de la derrota electoral de gobernadores provinciales del año 1987, con el peronismo, Alfonsín perdió fuerza y legitimidad, y eso es fundamental para inyectar adecuadas condiciones de gobernanza y gobernabilidad en el país. La historia del devenir de conflictos nos caracteriza a nivel internacional como una nación sin un proyecto de desarrollo claro. (Entrevista Pablo Gerchunoff, 2005).

De acuerdo con las entrevistas expuestas, se puede observar un punto de confluencia en las reflexiones hechas en perspectiva sociohistórica, respecto del fracaso del Plan Austral: el eje central del 
diseño e implementación de este plan era generar las bases para darle un mayor sustento de gobernabilidad democrática al gobierno de Alfonsín, puesto que mantener la democracia era tanto un imperativo moral como político. A partir de esta premisa, las consideraciones técnicas del Plan Austral, fueron sometidas a ciertas variaciones que afectaron su eficacia en el largo plazo y que terminaron fracasando, lo que llevó a su suspensión definitiva en el año 1988 y que generó, entre otras situaciones institucionales, que el presidente Alfonsín tomara la decisión de adelantar las elecciones presidenciales. La convicción que queda en los principales protagonistas del Plan Austral fue el intentar la aplicación de nuevas formas de gobernanza económica, cuyo propósito principal era una relación entre crecimiento y bienestar y, por sobre todo, entregar el gobierno a otro mandatario elegido democráticamente, como finalmente se dio, cuando asume el presidente Carlos Saúl Menem.

\section{Consideraciones finales del análisis de los resultados de la investigación}

A partir de las evidencias recopiladas, se puede establecer una reflexión sociológica, la que por cierto no pretende imponerse como una verdad absoluta, sino como un análisis que abre espacios de diálogo y discusión, tanto teórica como empírica. El Plan Austral desde su anuncio y durante los primeros tres meses, logró de buena forma los objetivos plasmados, lo que repercutió positivamente como una decisión de gobernanza que aumentó los niveles de gobernabilidad, esencial en el escenario político de un gobierno que enfrentaba la transición democrática en Argentina. Sin embargo, esta situación inicial auspiciosa se fue deteriorando paulatinamente, puesto que el gobierno de Alfonsín fue permeable a las presiones de ciertos actores políticos y sociales, por ejemplo los sindicatos, con una tradición de alto nivel de poder e influencia en las discusión de asuntos públicos del país. La discusión y negociación política con distintos actores es parte de la gobernabilidad democrática, pero abre ciertas condiciones de pérdida de eficacia en decisiones que buscan lograr equilibrios a nivel macro, como es el caso de la economía nacional en este relato histórico.

Desde un tratamiento analítico sociológico, la reflexión se sustentó en el marco teórico de la presente investigación. En efecto, el Plan 
Austral constituye un plan de gobernanza económica que se basó en fundamentos técnicos, y que se diseñó desde una mirada distinta de la hegemónica en esos tiempos, es decir, desde la heterodoxia. Sus propósitos fueron bien explicitados en su origen y lograron obtener resultados satisfactorios en su inicio.

En concordancia con la línea de tiempo señalada y de acuerdo con los postulados de Dahrendorf (1992; 1993), Coser (1970), Mallom y Vital Sourrouille (1973), entre otros, el país trasandino ha enfrentado tensiones en cuanto a la configuración del Estado, de las relaciones de poder, autoridad y legitimidad de las instituciones estatales. Por otra parte, actores no institucionales - movimientos sociales, obreros, políticos y sindicatos-, adquirieron influencia y capacidad de tensionar las relaciones institucionales. Así, Argentina se construye como un devenir de acuerdos de gobernanza y gobernabilidad con fracturas temporales cíclicas y permanentes, que afectan su estabilidad política económica y social. Tal como lo planteara Sidicaro (2002) respecto de la crisis del Estado argentino y lo expresado por Murmis y Portiantero (2011) respecto al legado que dejó el peronismo en las estructuras políticas y sociales de la nación trasandina, la sociedad conflictiva se manifiesta en la reacción contestataria al poder político y la forma de ejercer coerción. Este argumento también es validado por Gerchunoff y Rapetti (2016), en el sentido de recorrer la historia de Argentina durante el siglo XX, un siglo lleno de condiciones de conflicto, desarrollo y estancamiento, pasando por un período conservador (1930-1943), militarismo y populismo (1943-1966), el peronismo en dos tiempos relevantes (década del 50 y del 70), dictadura militar (1976-1983) y una transición democrática con fracturas institucionales (desde 1983 en adelante). Los sindicatos por ejemplo, plantean una lógica de permanente resistencia social al empresariado y al gobierno, y ven en el concepto de reivindicación, una bandera de lucha basada en una idea de igualdad.

Cabe destacar que de acuerdo con lo señalado por Murmis y Portantiero (2011) y ratificado en parte de los relatos analizados en el estudio de campo, se puede establecer que el peronismo como corriente de pensamiento y fuerza política, ha desarrollado un poder, influencia y capacidad de movilización que ha sido determinante en la configuración de las instituciones y la sociedad argentina, tensionando el con- 
cepto de conflicto social, bajo los argumentos de Dahrendorf (1993), en el sentido de establecer una dinámica de conflicto que moviliza permanentemente al poder, la autoridad, la gobernanza y la gobernabilidad de la nación trasandina.

También parece relevante destacar que el Plan Austral como noción instrumental de un plan de gobernanza económica, se vincula de cierta forma con lo planteado por Gerchunoff y Llach (2005), en el sentido de que estas experiencias normativas - que en algunos casos no generaron efectos positivos sostenibles en el tiempo-, sí dejan experiencias para comprender la economía más allá de lo técnico, y vincularla de mejor forma con la realidad política y social propia del tramado histórico argentino, aprendizajes que también dejó el Plan Pinedo del año 1940.

\section{Discusión y conclusiones}

A continuación, se desarrollará la discusión final y las conclusiones de los aspectos más sustantivos de la investigación realizada, enfatizando la respuesta a la pregunta central de investigación y objetivos, junto con una consideración final desde una perspectiva sociológica.

\section{Pregunta central de investigación}

La interrogante central que guio la presente investigación fue la siguiente: ¿Cómo se puede comprender, desde la teoría del conflicto social, la aplicación de una política económica neoestructural en Argentina entre 1985 y 1988 ?

Considerando los aspectos teóricos y empíricos de la investigación, se puede responder que en Argentina se formuló y ejecutó un plan de gobernanza económica denominado Plan Austral entre los años 1985 y 1988, bajo un esquema de lógica neoestructural, en el contexto de una sociedad conflictiva.

Es posible de desagregar la comprensión e interpretación de este plan en tres aspectos fundamentales: a) la aplicación de un plan económico neoestructural finalmente fallido; b) el contexto sociopolítico de aplicación del plan en una sociedad conflictiva; y c) el intento de establecer una visión distinta de relación entre la economía, la política y las relaciones sociales. 
Respecto del primer ámbito de comprensión, se puede establecer que el Plan Austral se diseña sobre la base ideas asociadas al neoestructuralismo. En efecto, el segundo equipo de conducción económica del presidente Alfonsín - comandado por el economista Juan Vital Sourrouille-, establece como prioridad en 1985 enfrentar el alto nivel de inflación en Argentina, lo que afectaba gravemente la demanda agregada, el crecimiento, la política monetaria y fiscal. Todo eso incidía gravemente en la situación socioeconómica de la sociedad trasandina, en especial los grupos de menores recursos. Sobre la base de un planteamiento de economía política, el grupo de economistas de gobierno establece una línea de pensamiento de desarrollo para Argentina, basada en su matriz productiva en el largo plazo, con un plan de acciones heterodoxas, alejándose de las políticas disciplinarias de carácter ortodoxo, comandadas por organismos internacionales tales como el FMI y el Banco Mundial.

En relación con los relatos de personeros de gobierno que participaron del Plan Austral, junto con otras evidencias que sustentaron el análisis sociológico, la reflexión apunta a que se trata de un plan fallido en sus efectos finales, es decir, no logró la estabilización macroeconómica de las variables de demanda agregada del país. Sin embargo, florece la convicción de haber intentado una fórmula desarrollista distinta, que apoyara al fortalecimiento de la institucionalidad democrática como concepto (North, 1990), y que permitiera avanzar en la transición democrática de Argentina en la década de los 80. Queda claro en el relato de los protagonistas del Plan Austral, el asumir el costo de oportunidad de no haber estabilizado la economía en el largo plazo, pero de mantener la democracia en el país y que el presidente Alfonsín entregara el mandato a otro gobierno democrático, como ocurrió finalmente.

En cuanto al segundo planteamiento, es decir, el contexto sociopolítico de aplicación del plan en una sociedad conflictiva, se puede establecer que el diseño e implementación del Plan Austral consideró el contexto sociopolítico. El ministro Vital Sourrouille ya había analizado años atrás - desde una perspectiva académica-, la compleja situación de implementar planes económicos en sociedades conflictivas como Argentina. Es por esta razón que el plan económico analizado se basó en un enfoque gradualista que buscaba mini- 
mizar los efectos de la presión política de sindicatos y otros grupos de interés.

En lo concerniente al tercer planteamiento, se releva el esfuerzo de establecer una visión distinta de relación entre la economía, la política y las relaciones sociales. Cuando en varios pasajes de los relatos se habla de un plan económico que se vincula con el neoestructuralismo y con un conjunto de acciones heterodoxas, lo que se plantea finalmente es una noción distinta de una idea de desarrollo, la que no solo quiere expresarse en estabilidad macroeconómica de variables como crecimiento, inflación, desempleo, política fiscal, política monetaria, comercio internacional e intervención de los ciclos económicos, basados en la economía ortodoxa. Dicha idea que se plasma incorpora un planteamiento desarrollista que lo expresa el neoestructuralismo como bienestar, equidad y desarrollo sustentable. Desde luego, la lectura del artículo invita a construir una opinión propia o a fomentar la búsqueda de literatura relacionada, para ver otros puntos de vista o miradas que amplíen el horizonte de análisis.

La investigación realizada, promueve una ventana de oportunidades para establecer una línea de investigación permanente, que logre hacer confluir los aportes de la economía, la ciencia política y la sociología. Considerando la situación económica y sociopolítica de América Latina en la actualidad, se hace cada vez más necesario el desarrollo de estudios que busquen explorar y comprender las dinámicas del cambio social propias del siglo XXI.

\section{Referencias}

Alfonsín, R. (1985). Presidente Alfonsín y Sourrouille, anuncia el Plan Austral, 1985 (Parte I). https://www.youtube.com/ watch?v=oZ4HAJJu_5g

Alfonsín, R. (2004). Memoria política. Transición a la democracia y derechos humanos. Fondo de Cultura Económica.

Alfonsín, R. (2005). Entrevista historia política y económica de Argentina. Archivos de Historial Oral, Instituto de Investigaciones Gino Germani, Facultad de Ciencias Sociales, Universidad de Buenos Aires, Argentina. 
Aróstegui, J. (1990). Sociología e historiografía en el análisis del cambio social reciente. Revista Historia Contemporánea, (4), 145172. http://hdl.handle.net/10810/37649

Ball, S. y Youdell, D. (2008). Hidden privatization in public education. Institute of Education, University of London.

Bárcena, A. y Prado, A. (Eds.) (2015). Neoestructuralismo y corrientes heterodoxas en América Latina y el Caribe a inicios del siglo XXI. Comisión Económica para América Latina y el Caribe, CEPAL.

Basualdo, E. (2006). Estudios de historia económica argentina. Desde mediados del siglo XX a la actualidad. Siglo XXI Editores.

Bonvecchi, C. (2005). Entrevista historia política y económica de Argentina. Archivos de Historial Oral, Instituto de Investigaciones Gino Germani, Facultad de Ciencias Sociales, Universidad de Buenos Aires, Argentina.

Bitar, S. (1988). Neoliberalismo versus neoestructuralismo en América Latina. Revista CEPAL, (34), 45-65. http://hdl.handle. net/11362/11690

Brodersohn, M. (2015). Entrevista historia política y económica de Argentina. Archivos de Historial Oral, Instituto de Investigaciones Gino Germani, Facultad de Ciencias Sociales, Universidad de Buenos Aires, Argentina.

Canales, M. (Coord.) (2013). Investigación social. Lenguajes del diseño. LOM ediciones.

Carballo, C. (2007). Entrevista historia política y económica de Argentina. Archivos de Historial Oral, Instituto de Investigaciones Gino Germani, Facultad de Ciencias Sociales, Universidad de Buenos Aires, Argentina.

Colomer Viadel, A. (Coord.). (1995). Economía, sociedad y Estado en América Latina contemporánea. Fondo de Cultura Económica.

Coser, L. (1970). Nuevos aportes a la teoría del conflicto social. Editorial Amorrortu.

Dahrendorf, R. (1966). Sociedad y libertad. Hacia un análisis sociológico de la actualidad. Editorial Tecnos.

Dahrendorf, R. (1992). Hacia una teoría del conflicto social. Fondo de Cultura Económica.

Dahrendorf, R. (1993). El conflicto social moderno. Ediciones Mondadori.

Decreto Nacional N 1.096, República de Argentina. (1985). Creación e implementación del Plan Austral. Boletín Oficial. 
Delgado, R. (2013). La herencia. Treinta años de economía argentina en democracia. Fondo de Cultura Económica.

Di Fillipo, A. (2009). Estructuralismo latinoamericano y teoría económica. Revista CEPAL, (98), 181-203. https://www.cepal.org/ es/publicaciones/11303-estructuralismo-latinoamericanoteoria-economica

Ffrench-Davis, R. (1988). Esbozo de un planteamiento neoestructuralista. Revista CEPAL. (34), 37-44. http://hdl.handle. net/11362/11688

Foxley, A. (1975). Estrategia de desarrollo y modelos de planificación. Fondo de Cultura Económica-Corporación de Estudios para Latinoamérica, CIEPLAN.

Frenklen, R. y Fanelli, J. M. (1986). El Plan Austral. Seminario sobre "Crisis externa y política económica: Los casos de Argentina, Brasil y México". CEPAL-Universidad Estadual de Campinas. http://hdl.handle.net/11362/33116

Friedman, M. (1962). The role of government in education. En Robert A. Solo (Ed.), Economics and the public interest (pp. 123-144). Rutgers University Press.

Friedman, M. y Friedman, R. (1980). Libre para elegir. Houghton Miffin Harcourt.

Gargarella, R. y Murillo, M. U. (Comps.) (2016). Discutir Alfonsín. Siglo XXI Editores.

Garulli, L. (2011a). Los desafíos de la transición democrática 1983-1989. Ediciones Universidad de Buenos Aires.

Garulli, L. (2011b). Consolidación y crisis de la democracia neoliberal. 1989-2001. Testimonios y documentos. Ediciones Universidad de Buenos Aires.

Gerchunoff, P. y Llach, L. (2005). El ciclo de la ilusión y el desencanto. Un siglo de políticas económicas argentinas. Editorial Ariel.

Gerchunoff, P. (2005). Entrevista historia política y económica de Argentina. Archivos de Historial Oral, Instituto de Investigaciones Gino Germani, Facultad de Ciencias Sociales, Universidad de Buenos Aires, Argentina.

Gerchunoff, P. y Rapetti, M. (2016). La economía argentina y su conflicto distributivo estructural (1930-2015). Revista El Trimestre Económico, 83(330), 225-272. https://doi.org/10.20430/ete. v83i330.199 
Hayek, F. A. (1976). Camino de servidumbre. Paidós.

Heredia, M. (2015). Cuando los economistas alcanzaron el poder. Siglo XXI Editores.

Hernández, R., Fernández, C., y Baptista, P. (2014). Metodología de la investigación. Mc Graw Hill.

Jencks, C. (2002). Does inequality matter. Daedalus, 131(1), 49-65.

Lavagna, R. (2007). Entrevista historia política y económica de Argentina. Archivos de Historial Oral, Instituto de Investigaciones Gino Germani, Facultad de Ciencias Sociales, Universidad de Buenos Aires, Argentina.

Machinea, J.L. (2005). Entrevista historia política y económica de Argentina. Archivos de Historial Oral, Instituto de Investigaciones Gino Germani, Facultad de Ciencias Sociales, Universidad de Buenos Aires, Argentina.

Mallom, P. y Vital Sourrouille, J. (1973). La política económica en una sociedad conflictiva. Editorial Amorrortu.

Mallorquín, C. (2017). Los orígenes del neoestructuralismo latinoamericano. Revista Estudios Regionales en Economía, Población y Desarrollo. Cuadernos de Trabajo de la UCAJ, 39(37), 1-41. http://erevistas.uacj.mx/ojs/index.php/estudiosregionales/ article/view/1704/1503

Mannheim, K. (2018). El hombre y la sociedad en la época de crisis. Centro de Investigaciones Sociológicas, CIS.

Martínez Carazo, P. (2006). El método de estudio de caso: estrategia metodológica de la investigación científica. Revista Pensamiento y Gestión, (20), 165-193.

Mises, L. V. (1972). Economic policy thoughts for today and tomorrow. (Six Lectures delivered in Buenos Aires in 1959). The Ludwig von Mises Institute. Regnery/Gateway Press.

Morales, J. J. (2010). José Medina Echevarría y la sociología del desarrollo. Revista Íconos de Ciencias Sociales, (36), 133-146. https:// www.redalyc.org/pdf/509/50912885012.pdf

Morales, J. J. e Ibacache, R. (2018). Democracia, sociedad y neoestructuralismo en el Chile de la transición (1988-1994). El papel de los economistas de CIEPLAN. En A. Falero, C. Quevedo y L. Soler (Eds.), Intelectuales, democracia y derechas (pp. 131159). CLACSO, El colectivo. 
Murmis, M. y Portantiero, J. C. (2011). Estudios sobre los orígenes del peronismo. Siglo XXI Editores.

Noreña, A., Alcaraz Moreno, N., Rojas J. G., y Rebolledo, L. (2012). Aplicabilidad de los criterios de rigor y éticos en la investigación cualitativa. Revista AQUICHAN, 12(3), 263274. http://www.scielo.org.co/scielo.php?pid=S1657$59972012000300006 \&$ script=sci_abstract\&tlng=es

North, D. (1990). Institutions, institutional change and economic performance. Cambridge University Press.

Nudelman, R. (1987). Raúl Alfonsín, el poder de la democracia argentina. Ediciones Fundación Plural.

Poterba, J. M. (1996). Government intervention in the markets for education and health care: How and why? En Victor R. Fuchs (Ed.), Individual and social responsibility: Child care, education, medical care, and long-term care in America (pp. 277308). University of Chicago Press.

Pucciarelli, A. (Coord.) (2010). Los años de Alfonsín. ¿El poder de la democracia o la democracia del poder? Siglo XXI Editores.

Quecedo, R. y Castaño, C. (2002). Introducción a la metodología de la investigación cualitativa. Revista de Psicodidáctica, (14), 5-39. https://www.redalyc.org/articulo.oa?id=17501402

Salgado, A. (2007). Investigación cualitativa: diseños, evaluación del rigor metodológico y retos. Revista Liberalit, 13(13), 71-78. http://www.scielo.org.pe/scielo.php?script=sci_arttext\&pid $=$ S1729-48272007000100009

Sidicaro, R. (2003). Consideraciones sociológicas sobre la Argentina de la Segunda Modernidad. Revista Estudios Sociales, 24, 127-152. http://2507-Texto del artículo-6146-1-10-20140305 (1).pdf

Sztulwark, S. (2005). El estructuralismo latinoamericano. Fundamentos y transformaciones del pensamiento económico de la periferia. Universidad Nacional del General Sarmiento.

Vital Sourrouille, J. (1985). Presidente Alfonsín y Sourrouille, anuncia el Plan Austral, 1985 (Parte II). https://www.youtube.com/ watch? $\mathrm{v}=5670 \mathrm{~W} 6 \mathrm{hS} 3 \mathrm{VQ}$

Vital Sourrouille, J. (2005). Entrevista historia política y económica de Argentina. Archivos de Historial Oral, Instituto de Investigaciones Gino Germani, Facultad de Ciencias Sociales, Universidad de Buenos Aires, Argentina. 